\title{
Extubation of a difficult airway after thyroidectomy: use of a flexible bronchoscope via the LMA-Classic ${ }^{\text {TM }}$ Extubation après une intubation difficile pour thyroïdectomie: utilisation d'un bronchoscope à fibres optiques via le LMA-Classic ${ }^{\text {TM }}$
}

\author{
Louise Ellard, MBBS • Dale H. Brown, MB BCh • \\ David T. Wong, MD
}

Received: 26 July 2011/ Accepted: 19 October 2011/Published online: 29 October 2011

(C) Canadian Anesthesiologists' Society 2011

\begin{abstract}
Purpose We report an extubation strategy for a patient scheduled for thyroidectomy who had several factors indicating that it would be a difficult extubation.

Clinical features A 75-yr-old man with thyroid cancer presented for total thyroidectomy. He had anatomical features predictive of a difficult upper airway. Therefore, his trachea was intubated while he was awake using a flexible bronchoscope. The tumour had invaded the trachea, necessitating total thyroidectomy, 3-cm tracheal resection, and primary tracheal anastomosis. The left recurrent laryngeal nerve (RLN) was inherently involved in the tumour and sacrificed. A "guardian suture" placed between the chin and the chest maintained the head and neck in flexion, thereby avoiding traction on the tracheal anastomosis. Immediate postoperative extubation was desirable, given the new tracheal anastomosis; however, complicating factors included left RLN paralysis, tracheal anastomosis, potential for tracheomalacia or supraglottic airway swelling, and the guardian suture preventing neck
\end{abstract}

L. Ellard, MBBS

Department of Anesthesia, University Health Network,

Toronto General Hospital, Toronto, ON, Canada

D. H. Brown, MB BCh

Department of Otolaryngology \& Head and Neck Surgery,

University Health Network, Princess Margaret Hospital,

Toronto, ON, Canada

D. T. Wong, MD ( $\varangle)$

Department of Anesthesia, University Health Network,

Toronto Western Hospital, 399 Bathurst St,

Toronto, ON M5T2S8, Canada

e-mail: david.wong@uhn.on.ca extension. In addition, there were anatomical features raising the suspicion of difficult reintubation should it be necessary. With the patient deeply anesthetized, the endotracheal tube was removed and replaced with the Laryngeal Mask Airway (LMA)-Classic ${ }^{T M}$ as a bridging device to facilitate bronchoscopic examination. It allowed us to visualize the tracheal repair, tracheal movement, vocal cord function, and supraglottic structures. The patient emerged from anesthesia and was extubated uneventfully.

Conclusion We describe a viable extubation strategy used in a patient after complex thyroid surgery involving tracheal resection. By using the LMA-Classic ${ }^{T M}$ as a bridging device and to facilitate bronchoscopic examination, we were able to address the above concerns and safely manage the extubation phase in this patient.

\section{Résumé}

Objectif Nous présentons les résultats d'une stratégie d'extubation pour un patient devant subir une thyroïdectomie et chez qui plusieurs facteurs indiquaient que l'extubation serait difficile.

Caractéristiques cliniques Un patient de 75 ans ayant un cancer de la thyroide devait subir une thyroidectomie totale. Ce patient présentait des caractéristiques anatomiques prédictives d'une intubation difficile. Sa trachée a donc été intubée à l'aide d'un bronchoscope à fibres optiques alors qu'il était éveillé. La tumeur avait envahi la trachée, nécessitant une thyroïdectomie totale, une résection trachéale de $3 \mathrm{~cm}$ et une anastomose trachéale primaire. Le nerf récurrent laryngé gauche était gravement touché par la tumeur et a été sacrifié. Une "suture du gardien », mise en place entre le menton et la poitrine, maintenait la tête et le 
cou en flexion, évitant ainsi toute traction sur l'anastomose de la trachée. L'extubation postopératoire immédiate était souhaitable, considérant la nouvelle anastomose trachéale; toutefois, plusieurs facteurs compliquaient la situation, notamment: la paralysie $d u$ nerf récurrent laryngé, l'anastomose trachéale, le risque de trachéomalacie ou d'oedème des voies aériennes supraglottiques, et la suture $d u$ gardien empêchant l'extension du cou. De plus, des caractéristiques anatomiques faisaient craindre qu'une réintubation, le cas échéant, serait difficile. Le patient étant profondément anesthésié, la sonde endotrachéale a été retirée et remplacée par un masque laryngé LMA-Classic ${ }^{T M}$ comme dispositif de transition pour faciliter l'examen bronchoscopique. Cela nous a permis de visualiser la réparation trachéale, les mouvements de la trachée, le fonctionnement des cordes vocales et les structures supraglottiques. Le patient s'est réveillé et a été extubé sans incident.

Conclusion Nous décrivons une stratégie d'extubation viable utilisée chez un patient après chirurgie complexe de la thyroïde impliquant une résection trachéale. En utilisant le LMA-Classic ${ }^{T M}$ comme dispositif de transition et pour faciliter l'examen bronchoscopique, nous avons pu répondre aux préoccupations énoncées ci-dessus et gérer de façon sécuritaire la phase d'extubation chez ce patient.

The strategy of using a supraglottic airway such as the Laryngeal Mask Airway (LMA)-Classic ${ }^{\mathrm{TM}}$ (LMA; LMA North America, San Diego, CA, USA) as a "bridging" device to prevent coughing and achieve smooth emergence after head and neck surgery has been described. ${ }^{1-3}$ An additional advantage of this technique after thyroidectomy is that the LMA provides a conduit for a flexible bronchoscope to visualize vocal cord function ${ }^{4}$ and verify the absence of tracheomalacia. ${ }^{5}$ Following tracheal resection, early extubation is desirable to avoid the effects of positive-pressure ventilation on the new anastomosis; devices crossing the new anastomosis are not ideal, and the chin-to-chest guardian suture increases the difficulty of reintubation. Numerous published case reports discuss extubation management after thyroidectomy ${ }^{4,5,11}$ or tracheal resection, ${ }^{10}$ and the described case required consideration of both.

Our patient was at "high risk" for a difficult extubation for several reasons. In addition to recognized unilateral recurrent laryngeal nerve (RLN) paralysis and potential tracheomalacia, there was a new tracheal resection and primary anastomosis, a guardian suture preventing neck extension, and a suspected difficult airway preoperatively. During the emergence phase, we used an LMA and bronchoscope to facilitate safe extubation. Written consent for publication of this article was obtained from the patient.

\section{Case report}

A 75-yr-old, 76-kg man with papillary thyroid cancer was scheduled for total thyroidectomy. Despite clinically significant tracheal compression and deviation seen on preoperative imaging, there was no stridor or dyspnea; and he was comfortable when fully supine. He was an ex-smoker and had a history of hypertension and gout.

Preoperative oxygen saturation was $95 \%$ on room air. His preoperative computed tomography scan showed compression and deviation of the trachea to the right (Fig. 1) due to a large left thyroid mass measuring $6.2 \times 3.8 \times 6.6 \mathrm{~cm}$ that extended inferiorly into the mediastinum. In addition, he had features suggesting a potentially difficult upper airway, including a Malampatti score of 3 , thyromental distance $<6.5 \mathrm{~cm}$, limited neck extension, and neck circumference $>40 \mathrm{~cm}$. We planned an awake oral bronchoscopic intubation.

Following application of routine monitors, intravenous and arterial access was obtained, and glycopyrrolate $0.2 \mathrm{mg}$ $i v$ was given. Local anesthesia for the awake intubation was achieved with $4 \%$ lidocaine (atomized) using soaked gauze applied to the oropharynx. Remifentanil was infused, commencing at $0.05 \mu \mathrm{g} \cdot \mathrm{kg}^{-1} \cdot \mathrm{min}^{-1}$. The bronchoscope was introduced orally, the vocal cords were identified, and the scope was passed into the trachea. At this time, an abnormality was observed on the lateral tracheal wall, raising the suspicion of tumour invasion into the trachea (Fig. 2). A size 7.0 reinforced endotracheal tube (ETT) was advanced easily to a point $2 \mathrm{~cm}$ above the carina. Following confirmation of correct ETT placement, general anesthesia and positive-pressure ventilation was commenced.

During the three-hour procedure, total thyroidectomy and neck dissection were completed. A large hole in the tracheal cartilage was evident, necessitating a tracheal

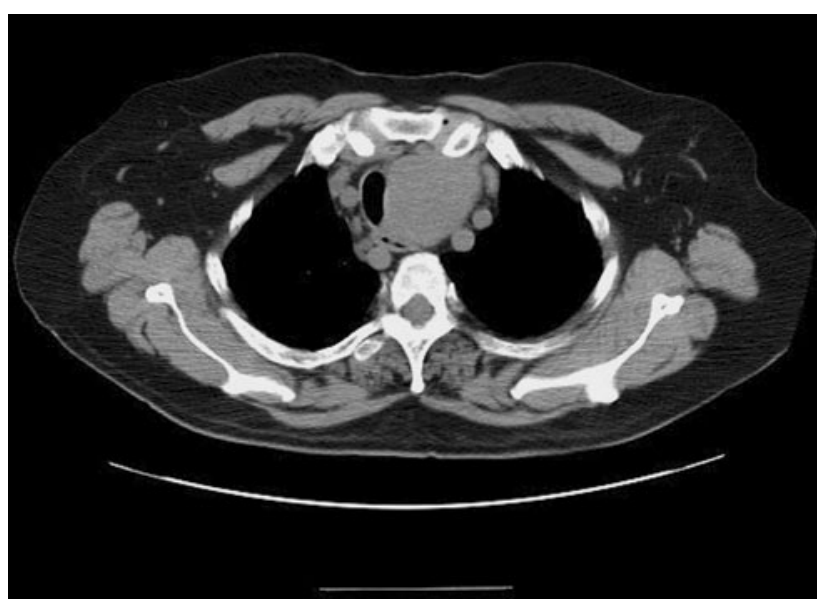

Fig. 1 Preoperative computed tomography shows compression and deviation of the trachea 


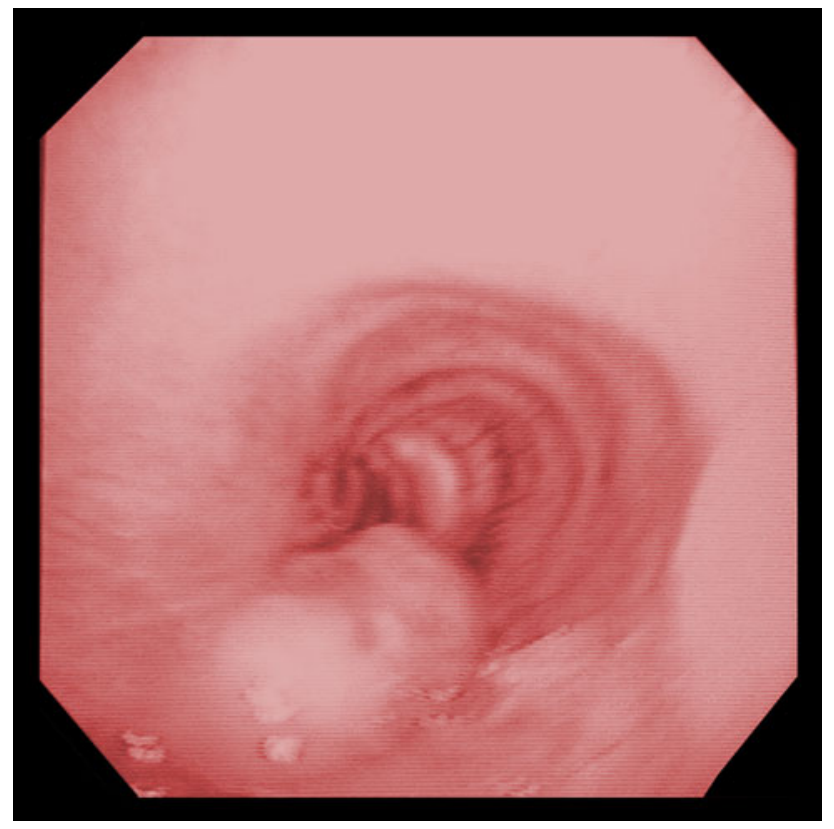

Fig. 2 Endoscopic image seen during the bronchoscopic intubation shows a tracheal abnormality

resection of approximately $3 \mathrm{~cm}$, with a primary tracheal anastomosis. The left RLN was inherently involved in tumour and sacrificed. A "guardian suture" was placed between the chin and the chest to prevent neck extension and tension on the tracheal anastomosis. ${ }^{6}$

The risks and benefits of immediate postoperative extubation were discussed with the surgeon. On the one hand, early extubation would have been desirable in this setting to avoid the potential adverse effects of positivepressure ventilation and the ETT cuff lying on a fresh tracheal anastomosis. ${ }^{7}$ However, the complicating factors of early extubation included left RLN paralysis, a new tracheal anastomosis, potential for tracheomalacia and supraglottic airway swelling, and the guardian suture preventing neck extension. In addition, there were preexisting anatomical features indicating a difficult airway.

An extubation strategy was required. Because examination of the vocal cords and subglottic airway is limited with an ETT in situ, our strategy was to replace the ETT with an LMA. Then, by inserting a bronchoscope via the LMA, we would be able to visualize the tracheal anastomosis, vocal cords, and supraglottic area. We were able to exclude potential reasons to delay extubation, and there was minimal risk of cough or airway obstruction during this phase. If there were any unanticipated abnormalities found during the bronchoscopic examination (i.e., bilateral vocal cord paralysis, supraglottic edema, tracheomalacia) we were prepared to reintubate the trachea using an Aintree Intubation Catheter (Cook Critical Care, Bloomington, IN, USA) and a flexible bronchoscope via the LMA. ${ }^{8}$

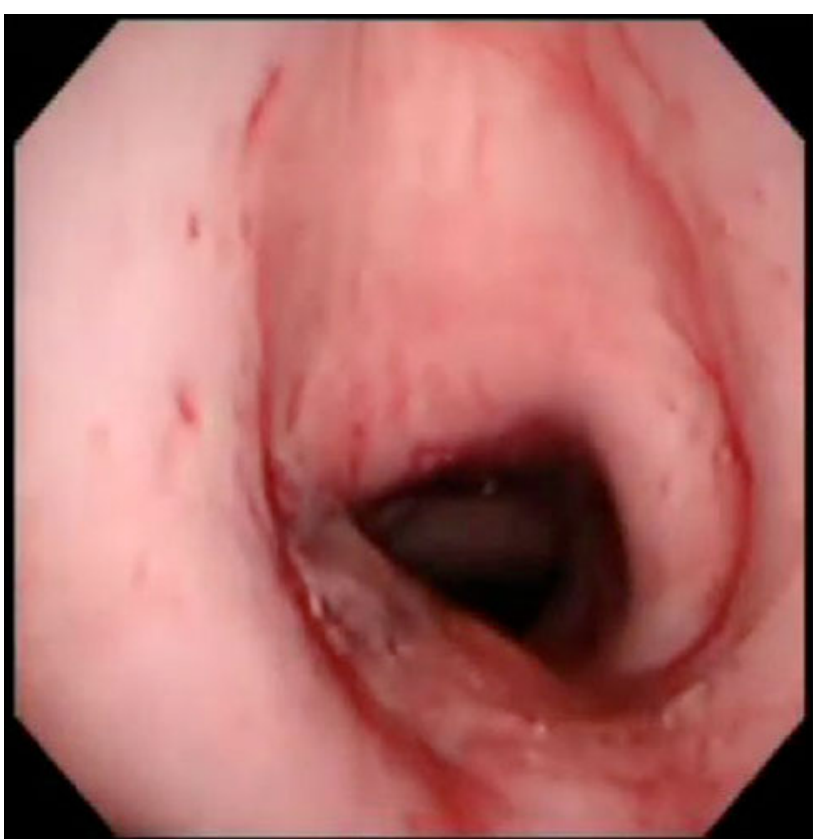

Fig. 3 Tracheal anastomosis is visualized using a flexible bronchoscope via the laryngeal mask airway prior to emergence

With the patient deeply anesthetized, the ETT was removed and replaced with a size 4 LMA. The bronchoscope was advanced through the vocal cords, and the surgeon was able to visualize the tracheal repair (Fig. 3). Muscle paralysis was then reversed, and spontaneous ventilation was reestablished; we were then able to exclude tracheomalacia. Left vocal cord paralysis was evident, and movement of the right vocal cord was confirmed (Fig. 4). No supraglottic edema was seen. The patient was allowed to emerge breathing spontaneously without coughing, and the LMA was removed uneventfully. Following observation in the recovery department for several hours, the patient was moved to a "step-down" unit on the ear/nose/ throat ward and had an uneventful recovery.

\section{Discussion}

The American Society of Anesthesiologists practice guidelines for management of the difficult airway recommend that, in addition to planning for intubation, the anesthesiologist should have a preformulated strategy for extubation of such patients. ${ }^{9}$ Our patient, after thyroidectomy and tracheal resection had been performed, fell into a high risk category for extubation, and reintubation could have been potentially difficult. We describe one extubation strategy that we employed. Just prior to emergence, the ETT was removed and replaced with an LMA as a bridging device to facilitate bronchoscopic examination of the tracheal repair, tracheal movement, vocal cord function, and supraglottic structures. 


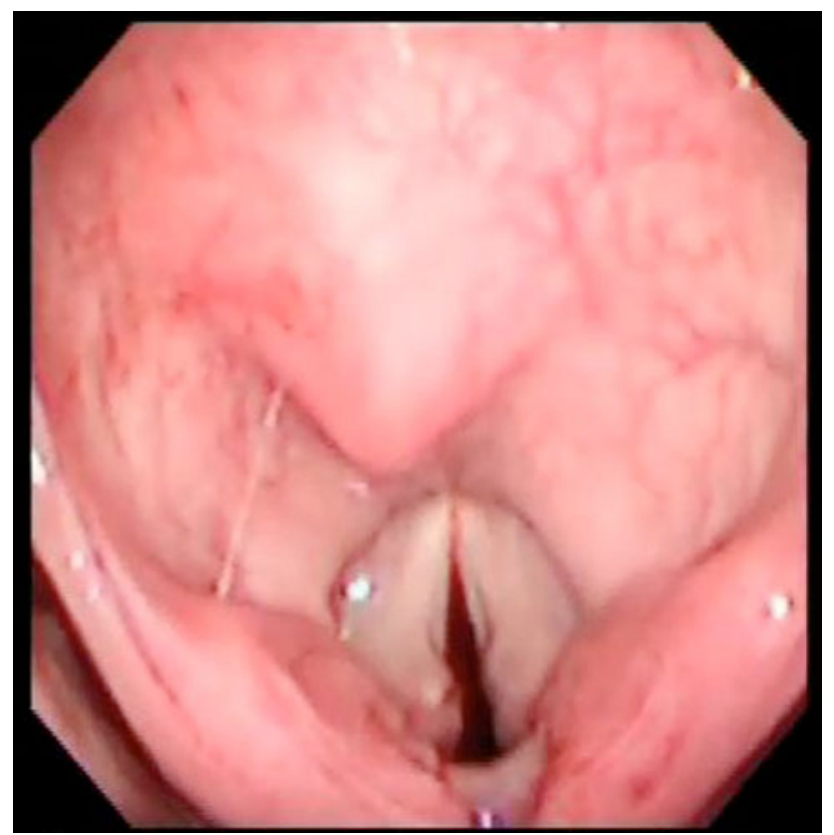

Fig. 4 Endoscopic confirmation of right vocal cord movement and left vocal cord paralysis prior to emergence

The patient was awakened, and the LMA was removed uneventfully. If bronchoscopic examination had revealed high-risk airway features, such as tracheomalacia or supraglottic edema, our plan was to reintubate using a bronchoscope and the Aintree catheter via the LMA.

There were several options for managing his extubation phase. The first option was to delay extubation for $24-48 \mathrm{hr}$ following a short stay in the intensive care unit. This was considered although only some of our concerns would be addressed with such a delay (i.e., supraglottic airway edema and the residual effects of anesthesia). We would still have faced the potential problems of vocal cord paralysis, tracheomalacia, and the anatomical features contributing to a potentially difficult reintubation. A second option was to perform a bronchoscopic examination via the ETT as it was withdrawn with the patient breathing spontaneously. With this strategy, the examination is likely to be short, as the patient is awakening, but it may induce coughing or laryngospasm. However, if unanticipated abnormalities are observed, tracheal reintubation is possible by readvancing the bronchoscope and railroading the tube over it. ${ }^{10}$ A third option was the use of a videolaryngoscope during the extubation phase to determine vocal cord function ${ }^{11}$ and verify the absence of supraglottic edema; this method would also assist with reintubation if required. However, it would not allow us to visualize the anastomosis or rule out tracheomalacia. Finally, we considered extubation over an airway exchange catheter, ${ }^{12}$ although we believed it was preferable to avoid devices crossing the new tracheal anastomosis.
Several case reports in the literature discuss extubation management after thyroidectomy, primarily discussing ways to reduce cough, identify vocal cord lesions, ${ }^{4,11}$ and exclude tracheomalacia. ${ }^{5}$ Similarly, descriptions of optimal management after a tracheal resection have been published. ${ }^{6,7,10}$ The uniqueness of our case was that we needed to combine both strategies to exclude potential postthyroidectomy complications, achieve a cough-free emergence, and avoid tension on the new tracheal anastomosis-all in a patient with a suspected difficult airway in whom reintubation would have been challenging.

There are several limitations to our chosen extubation strategy involving removal of the ETT and placement of a bridging LMA. First, after tracheal extubation, if there were significant supraglottic edema or infraglottic obstruction, ventilation via the LMA may have been difficult to achieve. However, the same situation may ensue if one had chosen the approach of conventional extubation of ETT when the patient is awakened. Second, after successful placement of the LMA, if a decision were made to reintubate, bronchoscopy-guided insertion of an Aintree Intubating Catheter or railroading an ETT over the Aintree Intubating Catheter may be difficult to achieve; and a backup plan of surgical airway insertion should be in place.

In conclusion, we described an extubation strategy used in a patient after complex thyroid surgery involving tracheal resection. By using an LMA as a bridging device and to facilitate bronchoscopic examination, we were able to visualize the tracheal repair, tracheal movement, vocal cord function, and supraglottic structures and safely manage the extubation phase in this patient. The bridging LMA also serves as a conduit for reintubation using a bronchoscope should clinically significant airway abnormalities be detected.

Conflicts of interest None declared.

\section{References}

1. Koga K, Asai T, Vaughan RS, Latto IP. Respiratory complications associated with tracheal extubation. Timing of tracheal extubation and use of the laryngeal mask during emergence from anesthesia. Anaesthesia 1998; 53: 540-4.

2. Nair I, Bailey PM. Use of the laryngeal mask for airway maintenance following tracheal extubation. Anaesthesia 1995; 50: 174-5.

3. Dob DP, Shannon CN, Bailey PM. Efficacy and safety of the laryngeal mask airway vs Guedel airway following tracheal extubation. Can J Anesth 1999; 46: 179-81.

4. Maroof M, Siddique M, Khan RM. Post-thyroidectomy vocal cord examination by fibreoscopy aided by the laryngeal mask airway. Anaesthesia 1992; 47: 445.

5. Palazzo FF, Allen JG, Greatorex RA. Laryngeal mask airway and fibre-optic tracheal inspection in thyroid surgery: a method for 
timely identification of tracheomalacia requiring tracheostomy. Ann R Coll Surg Engl 2000; 82: 141-2.

6. Pinsonneault $C$, Fortier J, Donati $F$. Tracheal resection and reconstruction. Can J Anesth 1999; 46: 439-55.

7. Sandberg $W$. Anesthesia and airway management for tracheal resection and reconstruction. Int Anesthesiol Clin 2000; 38: 55-75.

8. Cook TM, Seller C, Gupta K, Thornton M, O'Sullivan E. Nonconventional uses of the Aintree Intubating Catheter in management of the difficult airway. Anaesthesia 2007; 62: 169-74.

9. American Society of Anesthesiologists Task Force on Management of the Difficult Airway. Practice guidelines for management of the difficult airway: an updated report by the American Society of Anesthesiologists Task Force on Management of the Difficult Airway. Anaesthesiology 2003; 98: 1269-77.

10. Saravanan P, Marnane C, Morris EA. Extubation of the surgically resected airway-a role for remifentail and propofol infusions. Can J Anesth 2006; 53: 507-11.

11. Kikuchi C, Suzuki A, Iwasaki H. Verification of vocal cord function using the Pentax-AirwayScope ${ }^{\circledR}$. Can J Anesth 2007; 54: $1031-2$.

12. Mort TC. Continuous airway access for the difficult extubation: the efficacy of the airway exchange catheter. Anesth Analg 2007; 105: $1357-62$. 